\title{
Article \\ Clinical Significance of Histone Deacetylase (HDAC)-1, -2, -4 and -6 Expression in Salivary Gland Tumors
}

\author{
Despoina Pouloudi ${ }^{1,+}$, Maria Manou ${ }^{1,+}$, Panagiotis Sarantis ${ }^{1,2,+} \mathbb{D}$, Nikolaos Tsoukalas ${ }^{1}$, \\ Gerasimos Tsourouflis $^{3}\left(\mathbb{D}\right.$, Eougken Dana ${ }^{1}$, Michalis V. Karamouzis ${ }^{2} \mathbb{D}$, Jerzy Klijanienko ${ }^{4}$ (D) \\ and Stamatios Theocharis $1,4, *$ \\ 1 First Department of Pathology, Medical School, National and Kapodistrian University of Athens, \\ 11527 Athens, Greece; d.v.pouloudi@gmail.com (D.P.); maria_manou@hotmail.com (M.M.); \\ psarantis@med.uoa.gr (P.S.); ntsoukn@yahoo.gr (N.T.); eugenedanas@gmail.com (E.D.) \\ 2 Department of Biological Chemistry, Medical School, National and Kapodistrian University of Athens, \\ 11527 Athens, Greece; mkaramouz@med.uoa.gr \\ 3 2nd Department of Propedeutic Surgery, School of Medicine, National and Kapodistrian, \\ University of Athens, 11527 Athens, Greece; gtsourouflis@med.uoa.gr \\ 4 Department of Pathology, Institut Curie, 75248 Paris, France; jerzy.klijanienko@curie.fr \\ * Correspondence: stamtheo@med.uoa.gr or statheocharis@yahoo.com; Tel.: +30-210-7462116; \\ Fax: +30-210-7462157 \\ + These authors contributed equally to this manuscript.
}

check for updates

Citation: Pouloudi, D.; Manou, M.; Sarantis, P.; Tsoukalas, N.; Tsourouflis, G.; Dana, E.; Karamouzis, M.V.; Klijanienko, J.; Theocharis, S. Clinical Significance of Histone Deacetylase (HDAC)-1, -2, -4 and -6 Expression in Salivary Gland Tumors. Diagnostics 2021, 11, 517. https://doi.org/ 10.3390/diagnostics11030517

Academic Editor: Toshitaka Nagao

Received: 7 January 2021

Accepted: 11 March 2021

Published: 14 March 2021

Publisher's Note: MDPI stays neutral with regard to jurisdictional claims in published maps and institutional affiliations.

Copyright: (c) 2021 by the authors. Licensee MDPI, Basel, Switzerland. This article is an open access article distributed under the terms and conditions of the Creative Commons Attribution (CC BY) license (https:/ / creativecommons.org/licenses/by/ $4.0 /)$.

\begin{abstract}
Salivary gland tumors (SGTs) comprise a group of rare neoplasms. Locally aggressive, recurrent and/or metastatic SGTs are notorious for their resistance to systemic therapy, making the need for carefully designed, prospective and randomized trials with useful predictive markers mandatory to define new effective therapeutic protocols. Histone Deacetylases (HDACs), are thought to play a crucial role in carcinogenesis. They affect the DNA structure, being also able to regulate its transcription, repair, and replication. This study aimed to evaluate-to our knowledge for the first time- - the HDAC-1, -2, -4 and -6 immunohistochemical expression in SGTs and their potential use as prognostic biomarkers. Medical records and archival histopathological material of 58 (36 benign and 22 malignant) SGT patients were included in this study. The $H$-score was statistically correlated with the clinicopathological characteristics for all cases and patients' survival rate in malignant SGTs. HDAC-2 positivity was significantly associated with more prolonged overall survival (OS) of patients with malignant SGTs $(p=0.028)$, while HDAC-2 positivity and no HDAC-6 expression were associated with prolonged OS of patients with HG malignant SGT ( $p=0.003$ and $p=0.043$, respectively). Additionally, a high HDAC-2 H-score was significantly associated with longer OS for HG malignant SGT patients ( $p=0.027$ ). In our study, HDAC-2 expression is a marker for good prognosis, whereas HDAC-6 expression indicated poor prognosis; thus, an inhibitor of HDAC-6 may be used to improve patients' survival.
\end{abstract}

Keywords: HDAC; salivary gland cancer; immunohistochemistry; prognosis

\section{Introduction}

Salivary gland tumors (SGTs) comprise a group of rare neoplasms, accounting for 3\% to $10 \%$ of all head and neck tumors, characterized by histological diversity with-occasionally extensive-overlapping morphology and a broad spectrum of clinical behavior. The number of carcinoma types has increased from 5 in the 1972 WHO classification edition, to 22 in the 2017 one, and, in the same period, the number of benign tumors has increased from 4 to 11 [1,2]. Therefore, diagnostic and classification challenges are not uncommon [3]. Current research aims towards new immunohistochemical markers and molecular techniques to overcome these difficulties [4-9]. As far as malignant SGTs are concerned, their annual incidence ranges from 0.5 to 2 per 100,000 internationally [10]. Although 5-year survival 
is thought to be rather favorable for most of the distinct histologic types of SGT, survival rates seem to drop in the long-term, underlining that malignancy's lethal effect manifests itself late in the course of the disease [11]. Moreover, locally aggressive, recurrent and/or metastatic SGTs are notorious for their resistance to systemic therapy [12], making the need for carefully designed, prospective and randomized trials with useful predictive markers mandatory to define new effective therapeutic protocols $[13,14]$. Histone deacetylase inhibitors (HDACIs) are included among the numerous therapeutic regimens for the SGTs currently under study [15].

Nowadays, epigenetic phenomena are considered one of cancer's hallmarks, including SGTs $[16,17]$. Among them, post-translational modifications (PTMs) of DNA boundedhistones hold a crucial role in carcinogenesis. Histones are a heterogeneous group of proteins responsible for DNA condensation, representing the basic nucleosome component [18]. They affect the DNA structure being also able to regulate its transcription, repair and replication $[18,19]$. Histones are composed of a flexible "tail" susceptible to post-translation biochemical modifications, such as acetylation, methylation, ubiquitination and phosphorylation acetylation and methylation represents the most frequently described histones epigenetic modifications $[11,18,20]$. Histone acetylation on Lys residues, mediated by the histone acetyltransferase enzymes (HATs), is a common type of PTM that is highly reversible by a group of enzymes called Histone Deacetylases (HDACs). Histone deacetylation is associated with closed or repressive chromatin structure. Human HDACs comprise a group of 18 enzymes classified into four classes according to their sequence homology with $S$. cerevisiae yeast proteins: Class I includes HDAC-1, $-2,-3$ and -8, Class II is represented by HDAC-4, -5, -6, -7, -9 and -10, Class III includes SIRT1-7, and Class IV comprises HDAC-11 [21,22]. According to the Human Protein Atlas, different HDAC family members are abundantly expressed in a variety of human cancers, such as hematological malignancies, breast, renal, thyroid, GI tract, skin, lung cancer and more. In head and neck tumors HDAC - Class I and II members' expression (medium or high) ranges between $\sim 25 \%$ to almost $100 \%$, except HDAC-5, which is not detected in this group of cancers [23].

This study aimed to evaluate- for the first time to our knowledge- the HDAC-1, -2, -4 and -6 immunohistochemical expression in the group of rare and frequently challenging to manage SGTs. Furthermore, we aimed to investigate the possible correlations of HDAC-1, $-2,-4$ and -6 expression in malignant SGTs with clinicopathological characteristics and patients' survival and their potential use as prognostic biomarkers.

\section{Materials and Methods}

\subsection{Clinical Material}

Medical records and archival histopathological material of 58 SGT patients were included in this study. All patients were diagnosed and underwent surgical therapy within the period 2002-2017. None of the patients received any treatment before surgery. According to standard histopathological protocols, the corresponding surgical specimens were examined at the Department of Pathology of the Institut Curie. All cases were reviewed and classified (by J.K. and S.T.) according to the latest World Health Organization Classification principles [24].

The study sample consisted of 36 benign and 22 malignant cases. The group of benign tumors incorporated 28 Pleomorphic adenomas (PA), 7 Warthin tumors (WT) and 1 Basal cell adenoma (BAD). The group of malignant tumors incorporated 3 Mucoepidermoid carcinomas (MEC, 1 LG and 2 HG cases), 4 Adenoid cystic carcinomas (ACC, all HG cases), 5 Acinic cell carcinomas (AcCC, 2 LG and 3 HG cases), 1 Basal cell adenocarcinoma (BAC, LG case), 1 Salivary duct carcinoma (SDC, HG by definition), 1 Epithelial-myoepithelial carcinoma (EMC, HG) and 7 Squamous cell carcinomas (SCC, all HG cases).

Eighteen (18) of the patients were male (31.03\%), and 40 were female $(68.97 \%)$, with a male to female ratio of 0.44 for the benign and 0.47 for the malignant SGT cases. Overall mean age at diagnosis was 57.72 years (ranging from 28 to 85 years) and 71.14 years (ranging from 41 to 93 years) for benign and malignant SGT patients, respectively. 
During the observation period of patients with malignant SGTs, ranging from 10 to 170 months (median: 59.86 months), 6 patients died from their disease and 2 patients were alive with disease, whereas the remaining 14 patients were alive and free of disease.

\subsection{Immunohistochemistry}

Immunostainings for HDAC-1, $-2,-4$ and -6 were performed separately, on formalinfixed, paraffin-embedded (FFPE) SGT tissue sections, using rabbit polyclonal anti-HDAC-1 (H-51, sc-7872, Santa Cruz Biotechnology, Santa Cruz, CA, USA), rabbit polyclonal antiHDAC-2 (H-54, sc-7899, Santa Cruz Biotechnology), mouse monoclonal anti-HDAC-4 (A-4, sc-46672, Santa Cruz Biotechnology) and mouse monoclonal anti-HDAC-6 (D-11, sc-28386, Santa Cruz Biotechnology). In brief, $4 \mu \mathrm{m}$ thick tissue sections were dewaxed in xylene and brought to water through graded alcohols. Antigen retrieval was performed by microwaving slides in $10 \mathrm{mM}$ citrate buffer ( $\mathrm{pH}$ 6.0) for $15 \mathrm{~min}$ at high power. To remove the endogenous peroxidase activity, sections were then treated with freshly prepared $3 \%$ hydrogen peroxide in methanol in the dark for $10 \mathrm{~min}$ at room temperature. Nonspecific antibody binding was blocked using 5\% normal goat serum (NGS) for $1 \mathrm{~h}$. Tissue sections were incubated at $4{ }^{\circ} \mathrm{C}$ overnight against HDAC-1, $-2,-4$ and -6 diluted 1:100 in blocking buffer. Sections were then incubated at room temperature with biotinylated linking reagent (ab64264, Abcam, Cambridge, UK) for $10 \mathrm{~min}$, followed by incubation with peroxidase-conjugated streptavidin label (ab64264, Abcam) for $10 \mathrm{~min}$. The resultant immune peroxidase activity was developed using a diaminobenzidine (DAB) substrate kit (ab64264, Abcam, Cambridge, UK) for 10 min according to the manufacturer's instructions. Sections were counterstained with Harris' hematoxylin. Appropriate negative and positive controls were performed $[25,26]$.

\subsection{Evaluation of Immunohistochemistry}

Immunohistochemical evaluation was performed by two independent pathologists (S.T. and D.P.) with no knowledge of clinical data. Samples were considered "positive" for HDAC $-1,-2,-4$ and -6 when $>5 \%$ of tumor cells within the sample were stained. HDAC- 1 , $-2,-4$ and -6 immunoreactivity was estimated according to the percentage of positive tumor cells out of the total number of tumor cells within each specimen (0: negative staining, $0-4 \%, 1: 5-24 \%, 2: 25-49 \%$ and 3: $50-100 \%$ ) and staining intensity was scored as 0 : negative; 1: mild; 2: intermediate and 3: intense staining. The immunohistochemical $\mathrm{H}$-score of HDAC-1, $-2,-4$ and -6 was calculated for the predominant staining intensity, using the formula "intensity score + percentage of tumor cells." The expression of HDAC-1, $-2,-4$ and -6 was classified as low if the total score ( $H$ score) was $0-2$ and high if the overall score was $\geq 3$. In this way, we ensure that each group has a sufficient and more homogeneous number of comparable cases with the other groups $[25,26]$.

\subsection{Statistical Analysis}

The associations between HDAC-1, $-2,-4$ and -6 expression (nuclear and/or cytoplasmic) with clinicopathological variables were calculated with Chi-square test, while their correlations with clinical outcome, as far as malignant cases are concerned, were assessed by constructing survival curves, using the Kaplan-Meier method. It has been previously reported that the critical decision making in both diagnosis and treatment of SGT should be based on the tumors' histological subtype, and not on the specific pathological subtype. In this term, additional associations between benign and Low Grade (LG) and High Grade (HG) malignant cases have been conducted [27,28]. The differences between the curves were compared using the log-rank test. Results with a $p$-value of less than 0.05 were considered statistically significant. SPSS for Windows software was used for all analyses (SPSS Inc., V.25.0, Chicago, IL, USA). 


\section{Results}

All HDAC family members studied were abundantly expressed in SGTs (Figures 1 and 2).
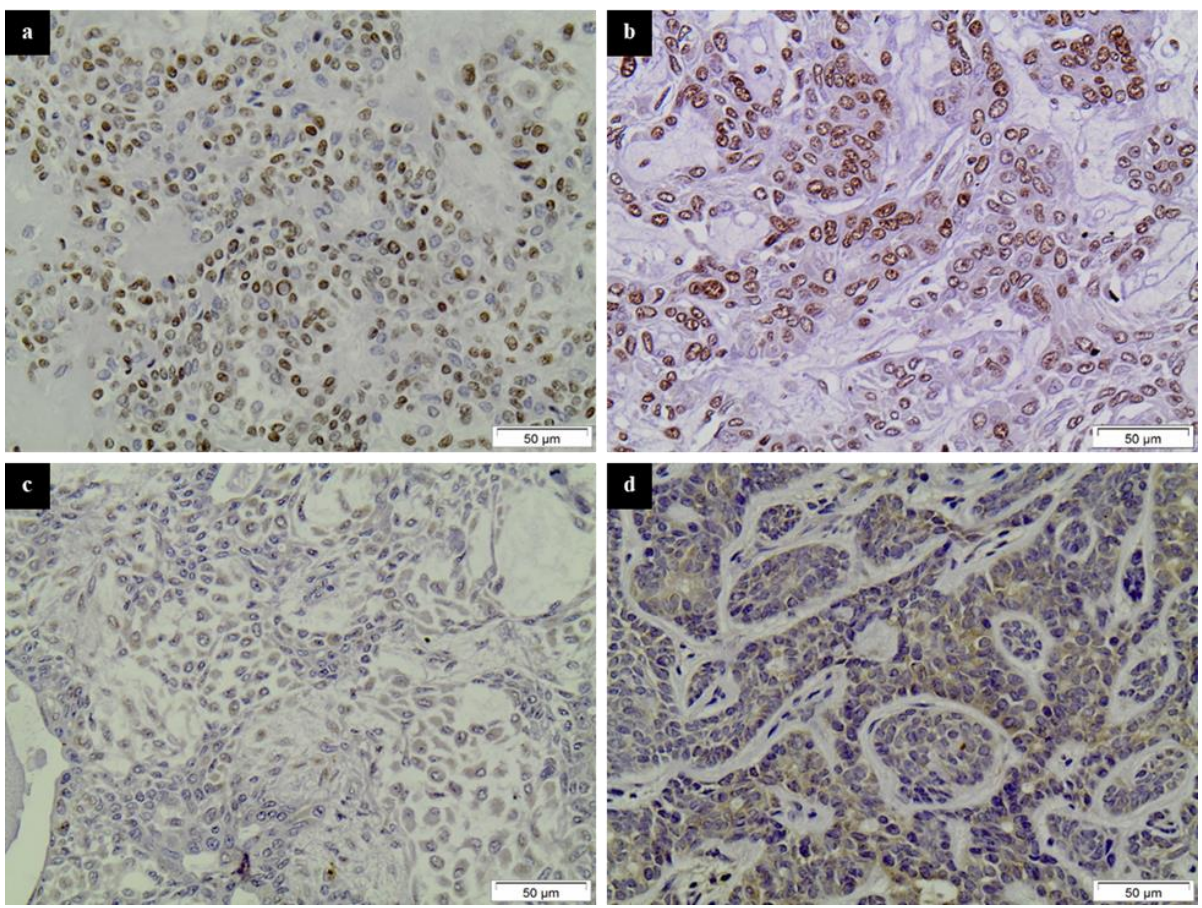

Figure 1. Representative immunostainings of HDAC-1, $-2,-4$ and -6 in benign SGTs. (a) HDAC-1 in a PA, (b) HDAC-2 in a PA, (c) HDAC-4 in a PA and (d) HDAC-6 in a BAD. Streptavidin-biotinperoxidase, $\mathrm{DAB}$ chromogen, Harris hematoxylin counterstain.
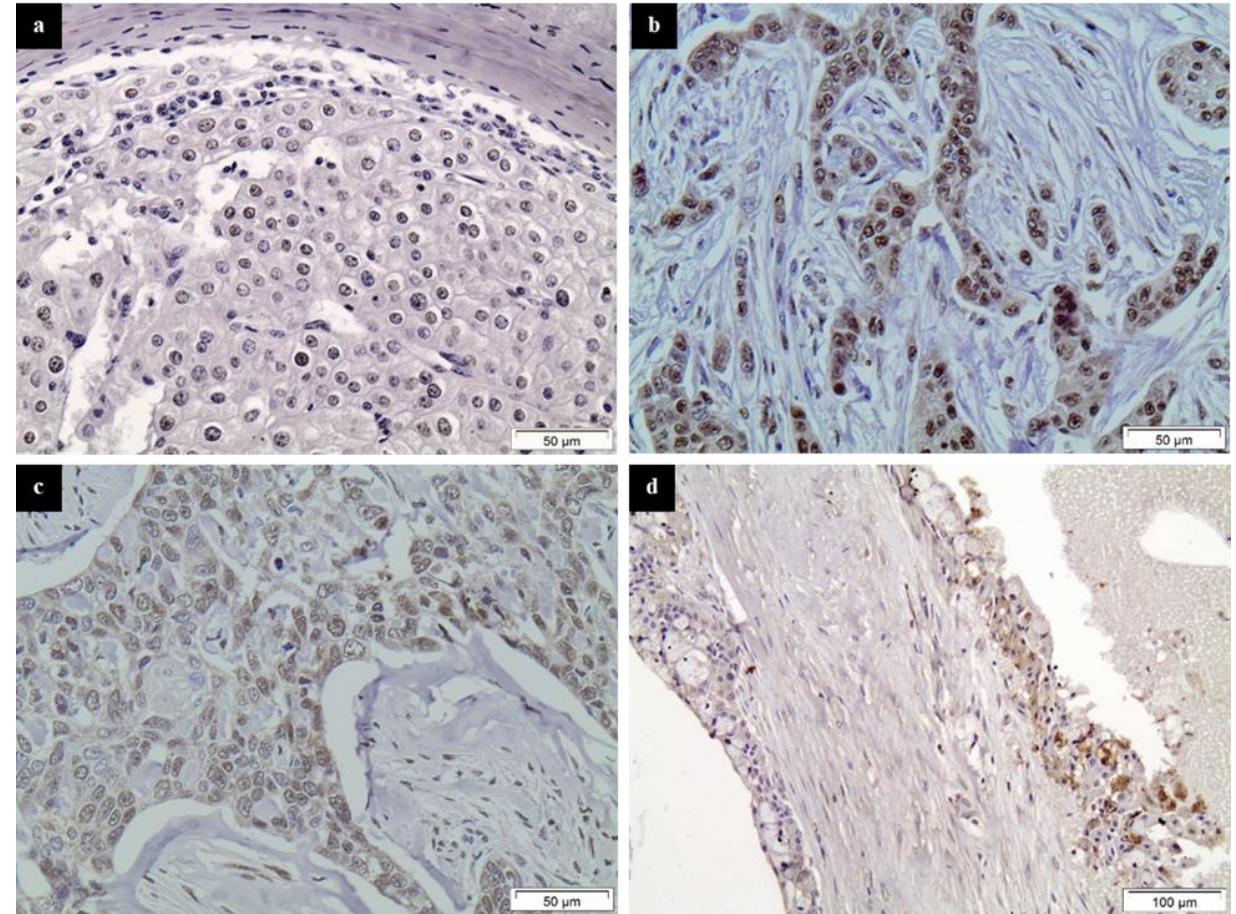

Figure 2. Representative immunostainings of HDAC-1, $-2,-4$ and -6 in malignant SGTs. (a) HDAC-1 in a HG ACC, (b) HDAC-2 in a HG SDC, (c) HDAC-4 in a HG SCC and (d) HDAC-6 in a HG MEC. Streptavidin-biotin-peroxidase, DAB chromogen, Harris hematoxylin counterstain. 
Class I HDAC-1 was expressed in about $31 \%$ of benign and $14 \%$ of malignant SGT cases with a nuclear distribution pattern. Class I HDAC-2 expression was detected in $86 \%$ of benign and $82 \%$ of malignant SGT cases. Interestingly enough, although the majority of tumors showed a nuclear staining pattern, cytoplasmic staining was also present in a few cases (2 PAs, 1 high-grade AcCC, 1 SDC and 1 SCC). Class IIa HDAC-4 stained $44 \%$ of benign and $36 \%$ of malignant tumors, mostly with a nuclear pattern, while 4 cases (different from the ones mentioned for HDAC-2) showed a cytoplasmic pattern of staining (3 PAs and 1 SCC). Finally, Class IIb HDAC- 6 was expressed in $11 \%$ of benign and $18 \%$ of malignant SGTs, mainly with a cytoplasmic staining pattern. More details about the results of the immunohistochemical analysis of benign and malignant SGTs are presented in Table 1.

HDAC intensity of staining did not statistically differ between benign, LG malignant and HG malignant SGTs, probably since some of the 10 distinct SGT entities studied were not satisfactorily represented because of their rarity. However, when grouping benign and LG malignant SGT cases together, staining intensity for HDAC-2 and HDAC-6 successfully differentiated HG malignant from benign plus LG malignant tumors ( $p=0.017$ and $p=0.028$, respectively) (Figure 3 ).
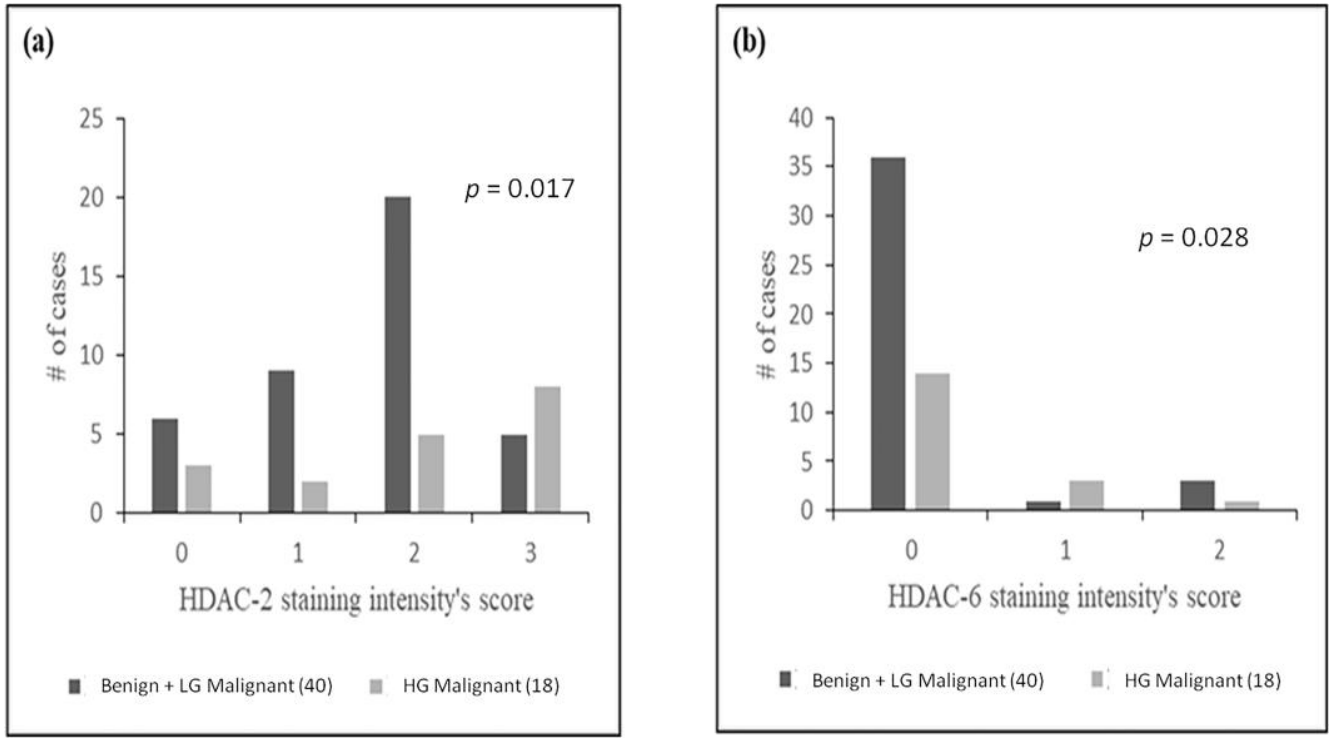

Figure 3. Correlation between staining intensity of (a) HDAC-2 and (b) HDAC-6 and benign plus LG malignant vs. HG malignant SGTs. 
Table 1. Detailed results of the immunohistochemical analysis of HDAC-1, $-2,-4$ and -6 expression in SGTs.

\begin{tabular}{|c|c|c|c|c|c|c|c|c|}
\hline \multirow{2}{*}{$\begin{array}{c}\text { HDAC } \\
\text { \# OF CASES }\end{array}$} & \multicolumn{2}{|c|}{ HDAC-1 } & \multicolumn{2}{|c|}{ HDAC-2 } & \multicolumn{2}{|c|}{ HDAC-4 } & \multicolumn{2}{|c|}{ HDAC-6 } \\
\hline & Positive (\%) & High $H$-Score $(\%)$ & Positive (\%) & High $H$-Score $(\%)$ & Positive (\%) & High $H$-Score (\%) & Positive (\%) & High $H$-Score $(\%)$ \\
\hline TOTAL (58) & $14(24.14 \%)$ & $4(6.90 \%)$ & $49(84.48 \%)$ & $44(75.86 \%)$ & $24(41.38 \%)$ & $13(22.41 \%)$ & $8(13.79 \%)$ & $4(6.90 \%)$ \\
\hline PA (28) & $10(35.71 \%)$ & $3(10.71 \%)$ & $26(92.86 \%)$ & $24(85.71 \%)$ & $15(53.57 \%)$ & $7(25 \%)$ & $3(10.71 \%)$ & $2(7.14 \%)$ \\
\hline WT (7) & $1(14.29 \%)$ & $0(0 \%)$ & $4(57.14 \%)$ & $3(42.86 \%)$ & $0(0 \%)$ & $0(0 \%)$ & $0(0 \%)$ & $0(0 \%)$ \\
\hline $\operatorname{BAD}(1)$ & $0(0 \%)$ & $0(0 \%)$ & $1(100 \%)$ & $1(100 \%)$ & $1(100 \%)$ & $1(100 \%)$ & $1(100 \%)$ & $1(100 \%)$ \\
\hline MALIGNANT (22) & $3(13.64 \%)$ & $1(4.55 \%)$ & $18(81.82 \%)$ & $16(72.73 \%)$ & $8(36.36 \%)$ & $5(22.73 \%)$ & $4(18.18 \%)$ & $1(4.55 \%)$ \\
\hline MEC (3) & $1(33.33 \%)$ & $1(33.33 \%)$ & $3(100 \%)$ & $3(100 \%)$ & $2(66.67 \%)$ & $2(66.67 \%)$ & $1(33.33 \%)$ & $0(0 \%)$ \\
\hline Low grade (1) & $0(0 \%)$ & $0(0 \%)$ & $1(100 \%)$ & $1(100 \%)$ & $0(0 \%)$ & $0(0 \%)$ & $0(0 \%)$ & $0(0 \%)$ \\
\hline High grade (2) & $1(50 \%)$ & $1(50 \%)$ & $2(100 \%)$ & $2(100 \%)$ & $2(100 \%)$ & $2(100 \%)$ & $1(50 \%)$ & $0(0 \%)$ \\
\hline $\mathrm{ACC}(4)$ & $1(25 \%)$ & $0(0 \%)$ & $4(100 \%)$ & $4(100 \%)$ & $0(0 \%)$ & $0(0 \%)$ & $0(0 \%)$ & $0(0 \%)$ \\
\hline Low grade (0) & - & $0(0 \%)$ & - & - & - & - & - & - \\
\hline High grade (4) & $1(25 \%)$ & $0(0 \%)$ & $4(100 \%)$ & $4(100 \%)$ & $0(0 \%)$ & $0(0 \%)$ & $0(0 \%)$ & $0(0 \%)$ \\
\hline $\operatorname{AcCC}(5)$ & $0(0 \%)$ & $0(0 \%)$ & $3(60 \%)$ & $2(40 \%)$ & $0(0 \%)$ & $0(0 \%)$ & $0(0 \%)$ & $0(0 \%)$ \\
\hline High grade (3) & $0(0 \%)$ & $0(0 \%)$ & $2(66.67 \%)$ & $2(66.67 \%)$ & $0(0 \%)$ & $0(0 \%)$ & $0(0 \%)$ & $0(0 \%)$ \\
\hline BAC (1) & $0(0 \%)$ & $0(0 \%)$ & $1(100 \%)$ & $1(100 \%)$ & $1(100 \%)$ & $1(100 \%)$ & $0(0 \%)$ & $0(0 \%)$ \\
\hline Low grade (1) & $0(0 \%)$ & $0(0 \%)$ & $1(100 \%)$ & $1(100 \%)$ & $1(100 \%)$ & $1(100 \%)$ & $0(0 \%)$ & $0(0 \%)$ \\
\hline High grade (0) & - & - & - & - & - & - & - & - \\
\hline SDC (1) & $1(100 \%)$ & $0(0 \%)$ & $1(100 \%)$ & $1(100 \%)$ & $0(0 \%)$ & $0(0 \%)$ & $1(100 \%)$ & $0(0 \%)$ \\
\hline Low grade (0) & $\begin{array}{c}1(1000) \\
-\end{array}$ & - & $\begin{array}{c}1(1000) \\
-\end{array}$ & $\begin{array}{c}1(100 / 0) \\
-\end{array}$ & - & - & $\begin{array}{c}1(1000) \\
-\end{array}$ & - \\
\hline High grade (1) & $1(100 \%)$ & $0(0 \%)$ & $1(100 \%)$ & $1(100 \%)$ & $0(0 \%)$ & $0(0 \%)$ & $1(100 \%)$ & $0(0 \%)$ \\
\hline EMC (1) & $0(0 \%)$ & $0(0 \%)$ & $1(100 \%)$ & $1(100 \%)$ & $0(0 \%)$ & $0(0 \%)$ & $0(0 \%)$ & $0(0 \%)$ \\
\hline Low grade (0) & - & - & - & - & - & - & - & - \\
\hline High grade (1) & $0(0 \%)$ & $0(0 \%)$ & $1(100 \%)$ & $1(100 \%)$ & $0(0 \%)$ & $0(0 \%)$ & $0(0 \%)$ & $0(0 \%)$ \\
\hline SCC (7) & $0(0 \%)$ & $0(0 \%)$ & $5(71.43 \%)$ & $4(57.14 \%)$ & $5(71.43 \%)$ & $2(28.57 \%)$ & $2(28.57 \%)$ & $1(14.29 \%)$ \\
\hline Low grade (0) & - & - & - & $\begin{array}{c}T(01.1 \mathrm{~T} / 0) \\
-\end{array}$ & $\begin{array}{c}- \\
0\end{array}$ & $\begin{array}{c}- \\
-\end{array}$ & $\begin{array}{c}2(20.0710) \\
-\end{array}$ & $\begin{array}{c}- \\
-\end{array}$ \\
\hline High grade (7) & $0(0 \%)$ & $0(0 \%)$ & $5(71.43 \%)$ & $4(57.14 \%)$ & $5(71.43 \%)$ & $2(28.57 \%)$ & $2(28.57 \%)$ & $1(14.29 \%)$ \\
\hline
\end{tabular}


HDAC-2 positivity was significantly associated with more prolonged overall survival (OS) of patients with malignant SGTs $(p=0.028$, Figure 4$)$.

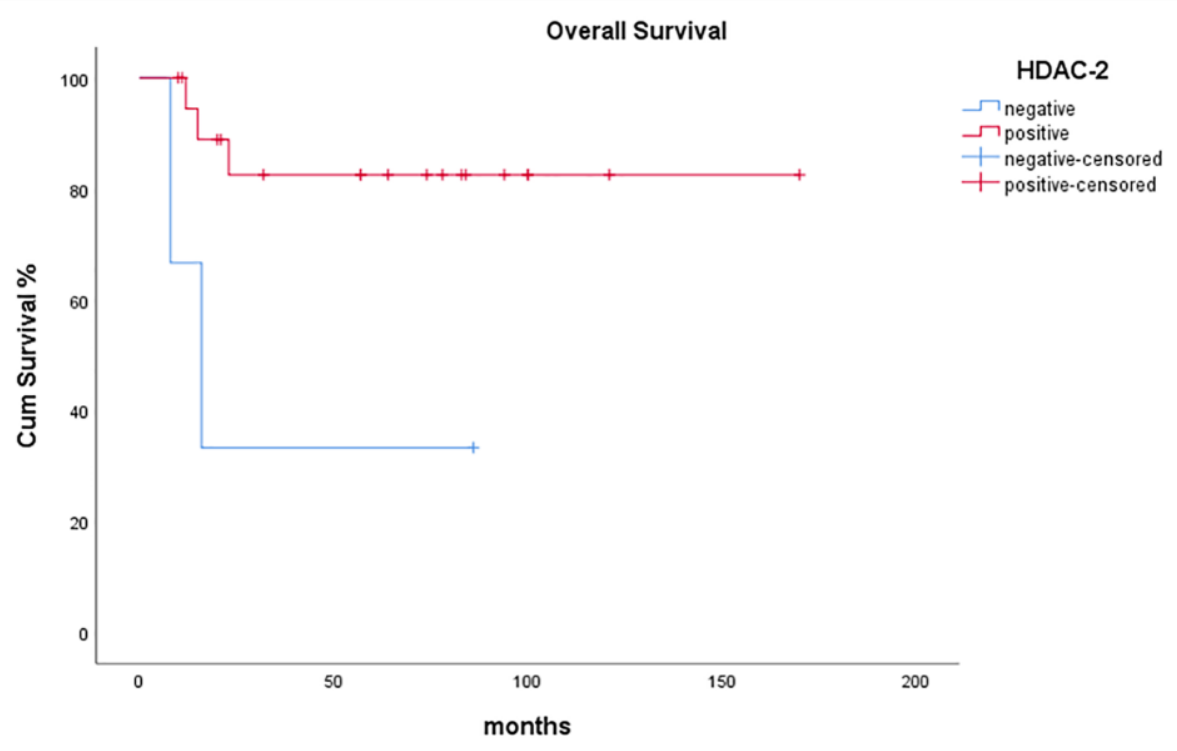

Figure 4. Kaplan-Meier survival analysis stratified according to HDAC-2 positivity in patients with malignant SGTs.

The favorable effect of HDAC-2 positivity was even more prominent for patients with HG malignant SGTs ( $p=0.003$, Figure 5).

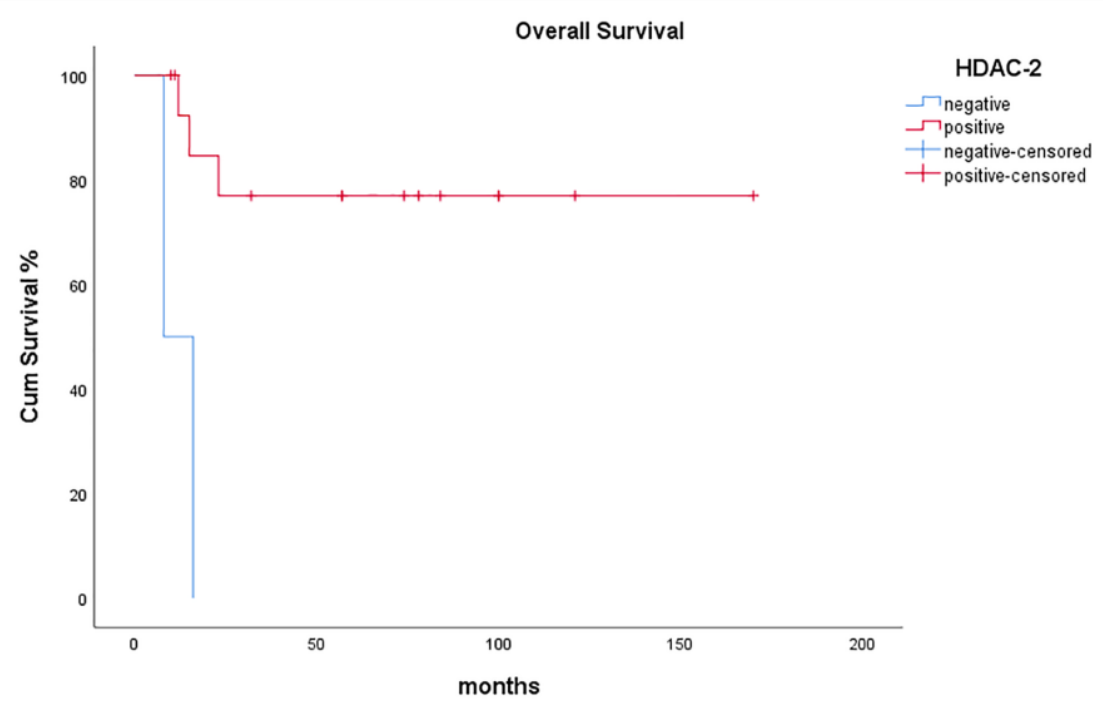

Figure 5. Kaplan-Meier survival analysis stratified according to HDAC-2 positivity in patients with HG malignant SGTs.

On the contrary, HDAC-6 positivity adversely affected OS of patients with HG malignant SGT, in the sense that no HDAC-6 expression was significantly associated with prolonged OS of these patients ( $p=0.043$, Figure 6). 


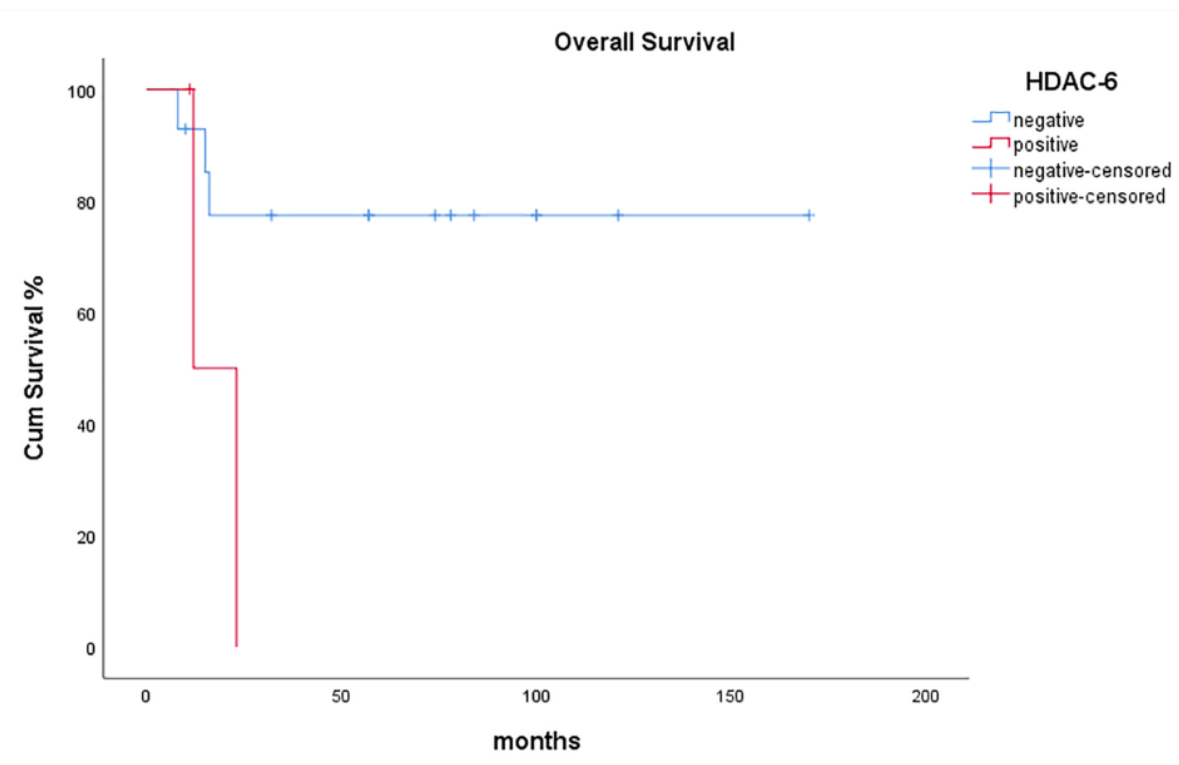

Figure 6. Kaplan-Meier survival analysis stratified according to HDAC-6 positivity in patients with HG malignant SGTs.

\section{Discussion}

Several studies during the last two decades have provided evidence of HDAC overexpression in numerous human cancers, underlining significant correlations between high HDAC levels and clinicopathological parameters pivotal for accurate diagnosis and patients' management, also providing prognostic information. In our study, which included 22 malignant SGT cases, HDAC-1, $-2,-4$ and -6 positivity was noted in $14 \%$ ( 3 out of 22 ), $82 \%$ ( 18 out of 22 ), $36 \%$ (8 out of 22 ) and $18 \%$ (4 out of 22 ), respectively. Additionally, high HDAC expression was noted in 33\% (1 out of 3), $89 \%$ (16 out of 18 ), $62.5 \%$ (5 out of 8 ) and $25 \%$ ( 1 out of 4 ) of HDAC-1, $-2,-4$ and -6 positive SGTs, respectively (Table 1 ).

Although no statistically significant associations between HDAC expression and patients' age and gender were recorded in our study, such correlations on different cancer types were found in other studies. More specifically, high HDAC-1 expression has been correlated with older patients' age in gastric carcinoma [29] and with younger patients' age and male gender in mobile tongue SCC [26]. In comparison, high HDAC-6 expression has been associated with younger patients' age in invasive ductal breast carcinoma cases [30].

Positive correlations between high HDAC expression and tumor differentiation levels have also been assessed in numerous studies, especially Class I HDACs members. In our study, both Class I members, HDAC- 1 and -2 and Class II members HDAC- 4 and -6 , were abundantly expressed in SGTs. The high number of distinct entities-most of them rare-studied herein ( 3 benign and 7 malignant histologic types of tumors) resulted in a disproportionate representation of each of them, posing restrictions on data analysis. However, HDAC-2 and HDAC-6 positivity were more frequently noted in HG SGTs when compared to the group of LG SGTs plus benign SGTs ( $p=0.017$ and $p=0.028$, respectively). Our findings imply an inversely proportional association of HDAC-2 and -6 positivity with tumor differentiation grade.

HDAC-1 overexpression has been significantly associated with glioblastoma [31] (HG by definition) and poorly differentiated mobile tongue SCC [26], lip SCC [32], non-small cell lung (NSCLC) [33], hepatocellular [34], prostate [35,36], serous subtype of endometrial and ovarian [37] and urothelial bladder carcinoma [38]. On the contrary, Suzuki et al. [39], who have reported a gradual reduction of HDAC-1, -2 , and -6 expression in the progression from healthy breast tissue to in situ and to invasive carcinoma, came up with a more significant HDAC-1 reduction in HG versus LG cases.

HDAC-2 overexpression has been correlated with HG lip SCC [32], NSCLC [33], esophageal [40], gastric $[29,41]$, hepatocellular [34], prostate [35,36], serous subtype of 
endometrial and ovarian and urothelial bladder carcinoma [38], the latest more often accompanied by adjacent carcinoma in situ when HDAC-2 was overexpressed [37].

HDAC-3 overexpression has been shown in glioblastoma (grade IV by definition) [31] and poorly differentiated hepatocellular [34], prostate [35,36], serous subtype of endometrial and ovarian [37] and urothelial bladder carcinoma [38].

Observations regarding associations between HDAC family members' overexpression and patients' OS and/or DFS rates are also highly significant. In our study, after a mean follow-up period of 59.86 months, 14 patients with malignant SGT were alive and diseasefree and 2 had a relapse, while 6 died of their disease. HDAC-2 positivity was significantly associated with prolonged OS of patients with malignant SGTs $(p=0.028)$. The association of HDAC-2 positivity and prolonged OS was even more prominent in HG malignant SGT cases $(p=0.003)$. On the contrary, HDAC- 6 overexpression adversely affected HG malignant SGT patients since the absence of HDAC- 6 expression was significantly associated with prolonged OS $(p=0.043)$.

HDAC-1 overexpression has been correlated with poor survival in mobile tongue SCC [25], gastric [29,41] and colorectal carcinoma [42], intrahepatic cholangiocarcinoma [43] and urothelial bladder endometrial and ovarian carcinoma [38], especially of endometrioid type [37,44]. Contrariwise, high levels of HDAC-1 expression have been connected with favorable prognosis in invasive breast $[30,45]$ and pancreatic carcinoma [46].

HDAC-2 overexpression has been associated with poor prognosis in patients with gastric [41], colorectal [42], hepatocellular [34,47] and prostate carcinoma (especially Gleason score 7 cases) [35], while it has been connected with prolonged survival in invasive breast carcinoma cases [29].

HDAC-3 overexpression has been found to correlate with shorter survival rates in gastric [40], hepatocellular carcinoma [33,46] and glioblastoma [31], whereas it has been associated with prolonged survival in primary and stage IV metastatic melanoma cases [48].

No relevant data have been reported for HDAC-4, while high HDAC-6 expression has been emerging as a favorable prognostic factor in terms of survival in invasive breast [30] and pancreatic cancer [46].

Additionally, Class IIa members, HDAC-5 and -9, have been found to correlate with poor survival rates in medulloblastoma cases [49], while HDAC-7 overexpression has been related to significantly higher number of deaths and recurrences in pancreatic cancer [50].

In our study, tumor size for SGTs varied between 0.5 and $6 \mathrm{~cm}$, lymph node metastasis was reported only in two cases, while there was no case with distant metastasis. Therefore, no significant correlations between tumor stage and HDAC subtypes overexpression could be identified. However, elevated HDAC expression has mainly been associated with advanced cancer stage in terms of tumor size, lymphatic/vascular invasion and presence of lymph node and/or distant metastases.

HDAC-1 overexpression has been connected with advanced disease stage in cases of mobile tongue SCC [25], NSCLC [33], primary or recurrent gastric cancer [41,51,52] and intrahepatic cholangiocarcinoma [43]. On the contrary, heterogeneous HDAC-1 expression (high and low) has been correlated with lymph node metastasis in colorectal cancer [53].

HDAC-2 overexpression has also been associated with advanced disease stage in thyroid [26], NSCLC [33] and gastric cancer [41,54]. Additionally, high HDAC-2 expression, in terms of intense staining intensity, has been significantly correlated with muscular invasion and advanced depth of invasion in mobile tongue SCC cases [25].

HDAC-3 overexpression has been inversely associated with $\mathrm{pT}$ status in a cohort of renal carcinomas (RCC), especially of the papillary histologic type [55].

High HDAC-4 expression has been connected with capsular invasion in malignant thyroid lesions [26] and advanced-stage epithelial ovarian cancer [56]. On the contrary, high HDAC-4 expression has been correlated with the absence of organ and lymph node metastases in pancreatic adenocarcinoma [46]. 
HDAC-5 (as well as HDAC-1, -2, -3 and -4) expression in prostate carcinomas is two-fold higher in pT3 compared to pT2 cases and to connect with tumor recurrence and metastasis [57].

Finally, HDAC-6 overexpression has been connected with advanced stages (III and IV) in oral SCC cases [58]. Contrariwise, it has been associated with earlier histopathological stage and smaller tumor size in pancreatic adenocarcinoma cases [46].

Extensive research of HDACs' impact on carcinogenesis has led to a group of potent epigenetic drugs. HDACs have already been approved for the treatment of cutaneous T-cell lymphoma, peripheral T-cell lymphoma and multiple myeloma. They are undergoing clinical trials - alone or in combination with other drugs- to treat numerous other cancers, such as lung, colorectal, cervical and ovarian, prostate and head and neck SCC [59]. Nevertheless, the studies using such drugs in SGT as a target for therapy are still limited [11].

Our study is the first to assess immunohistochemically the expression of HDAC family members in SGT tissue samples. Available data concerning the role of HDACs in SGTs remain scarce and HDACIs have been tried in SGTs without preceding evaluation of their expression levels. Wagner et al. [60] have recently immunohistochemically analyzed acetylhistone H3 expression and Ki67 index in tissue microarrays (TMAs) of 84 cases of SGTs, providing evidence that malignant SGTs were hypo-acetylated compared to benign ones. They also showed that levels of acetyl-histone H3 were inversely correlated with Ki67 index of SGTs, suggesting that HDACs promote cell proliferation. Simultaneously, Ahn et al. [61] investigated the specific inhibition of HDAC-7 expression in apicidin (HDACI)-treated MEC cell lines, providing evidence that HDAC-7 downregulation inhibits cell proliferation and induces autophagy in MEC cells. Wagner et al. [62] also explored the benefits of HDACs and NFKB combined inhibition with the administration of Vorinostat (HDACI) and Emetine, respectively, in MEC cell lines, showing that Vorinostat efficiently disrupted the population of cancer stem cells (CSCs). Moreover, it failed in significantly reducing the total number of tumor cells. When combined, however, Vorinostat plus Emetine provided an effective regimen for managing MECs. Another contemporary study by Almeida et al. [63] investigated the effect of Vorinostat and cisplatin, alone or in combination on ACC cell lines, considering CSCs as a biological marker of therapy resistance in patient-derived xenograft (PDX) samples and ACC primary cells. Researchers concluded that Vorinostat's administration reduces tumor cell viability and diminishes several detectable CSCs, with the effects being multiplied when combined with cisplatin. The same group of researchers had previously implied that sequential administration of Vorinostat and cisplatin (tow-hit regimen) minimizes the number of CSCs and prevents resistance in MEC cell lines [64]. The effect of chidamide, another HDACI, on human ACC cancer cells has also been assessed recently by western blot analysis of ACC cell lines [65]. Researchers presented evidence that chidamide induced histone-H3 acetylation resulting in diminished cell proliferation and cell-cycle arrest.

\section{Conclusions}

In our study, HDAC-2 expression emerges as an essential positive prognostic factor for SGT (good prognosis), whereas HDAC-6 expression as a negative one (poor prognosis). In addition, once the HDAC-6 overexpression is correlated with poor prognosis, an inhibitor of HDAC-6 may be used to improve patients' survival. Although our work supports statistically significant results of clinical importance, the main criticism of such studies remains the small number of patients with rare neoplasms enrolled and the heterogeneity of the histological groups within studies. Further work, in larger cohorts of specific SGT histological subtypes, is mandatory to verify the essential prognostic role of HDACs in SGTs and/or unlock their potential as therapeutic targets, using HDACIs for SGT patients' management.

Author Contributions: Conceptualization, D.P., M.M., J.K. and S.T.; Methodology, M.M., E.D. and P.S.; Software, P.S., N.T. and G.T.; Validation, G.T., M.V.K., J.K. and S.T.; Formal Analysis, N.T.; Investigation, E.D.; Resources, N.T.; Data Curation, G.T.; Writing-Original Draft Preparation, D.P., 
M.M. and P.S.; Writing-Review and Editing, M.V.K. and S.T.; Visualization, J.K.; Supervision, S.T.; Project Administration, J.K. and S.T.; Funding Acquisition, N.T. All authors have read and agreed to the published version of the manuscript.

Funding: The work of the authors was co-funded by the European Union (ESF) and Greek national funds through the Operational Program "Human Resources Development, Education and Lifelong Learning," project title "Immunohistochemical Investigation of Angiogenesis and Biological Behavior of Salivary Gland Tumors" (project code: 5007067).

Institutional Review Board Statement: The study was conducted according to the guidelines of the Declaration of Helsinki, and approved by the Ethics Committee of Medical Scool of the University of Athens (protocol code 108 and date 15-04-2019).

Informed Consent Statement: Informed consent was obtained from all subjects involved in the study.

Data Availability Statement: The data presented in this study are available on request from the corresponding author. The data are not publicly available due to ethical reasons.

Conflicts of Interest: The authors declare no conflict of interest.

\section{References}

1. Seifert, G.; Brocheriou, C.; Cardesa, A.; Eveson, J.W. World Health Organization (WHO) international histological classification of tumours tentative histological classification of salivary gland tumours. Pathol. Res. Pract. 1990, 186, 555-581. [CrossRef]

2. EI-Naggar, J.; Chan, K.C.; Grandis, J.R.; Takata, T.; Pieter, J.; Slootweg, A.K. World Health Organization Classification of Head and Neck Tumours, 4th ed.; IARC Publications: Lyon, France, 2017; ISBN 9789283224389.

3. Hellquist, H.; Paiva-Correia, A.; Poorten, V.V.; Quer, M.; Hernandez-Prera, J.C.; Andreasen, S.; Zbären, P.; Skalova, A.; Rinaldo, A.; Ferlito, A. Analysis of the clinical relevance of histological classification of benign epithelial salivary gland tumours. Adv. Ther. 2019, 36, 1950-1974. [CrossRef]

4. Griffith, C.C.; Schmitt, A.C.; Little, J.L.; Magliocca, K.R. New developments in salivary gland pathology: Clinically useful ancillary testing and new potentially targetable molecular alterations. Arch. Pathol. Lab. Med. 2017, 141, 381-395. [CrossRef] [PubMed]

5. Katabi, N.; Xu, B. Salivary gland neoplasms: Diagnostic approach with focus on patterns of recognition and useful ancillary tools. Diagn. Histopathol. 2018, 24, 180-188. [CrossRef]

6. Theocharis, S.; Gribilas, G.; Giaginis, C.; Patsouris, E.; Klijanienko, J. Angiogenesis in salivary gland tumors: From clinical significance to treatment. Expert Opin. Ther. Targets 2015, 19, 807-819. [CrossRef] [PubMed]

7. Yin, L.X.; Ha, P.K. Genetic alterations in salivary gland cancers. Cancer 2016, 122, 1822-1831. [CrossRef] [PubMed]

8. Carlson, E.R.; Schlieve, T. Salivary gland malignancies. Oral Maxillofac. Surg. Clin. N. Am. 2019, 31, 125-144. [CrossRef] [PubMed]

9. Lorenzo-Pouso, A.I.; Pérez-Sayáns, M.; Bravo, S.B.; López-Jornet, P.; García-Vence, M.; Alonso-Sampedro, M.; Carballo, J.; GarcíaGarcía, A.; Zalewska, A. Protein-based salivary profiles as novel biomarkers for oral diseases. Dis. Markers 2018, $2018,6141845$. [CrossRef] [PubMed]

10. To, V.S.H.; Chan, J.Y.W.; Tsang, R.K.Y.; Wei, W.I. Review of salivary gland neoplasms. ISRN Otolaryngol. 2012, 2012, 1-6. [CrossRef]

11. Israel, Y.; Rachmiel, A.; Gourevich, K.; Nagler, R. Survival probabilities related to histology, grade and stage in patients with salivary gland tumors. Anticancer Res. 2019, 39, 641-647. [CrossRef]

12. Chintakuntlawar, A.V.; Okuno, S.H.; Price, K.A. Systemic therapy for recurrent or metastatic salivary gland malignancies. Cancers Head Neck 2016, 1, 11. [CrossRef] [PubMed]

13. Bell, D.; Hanna, E.Y. Salivary gland cancers: Biology and molecular targets for therapy. Curr. Oncol. Rep. 2012, 14, 166-174. [CrossRef] [PubMed]

14. Theocharis, S.; Tasoulas, J.; Masaoutis, C.; Kokkali, S.; Klijanienko, J. Salivary gland cancer in the era of immunotherapy: Can we exploit tumor microenvironment? Expert Opin. Ther. Targets 2020, 24, 1047-1059. [CrossRef] [PubMed]

15. Rack, S.; Rahman, R.; Carter, L.; McKay, C.; Metcalf, R. Impact of tumour profiling on clinical trials in salivary gland cancer. Clin. Otolaryngol. 2019, 44, 1-6. [CrossRef] [PubMed]

16. Santos, E.S.; Ramos, J.C.; Normando, A.G.C.; Mariano, F.V.; Paes Leme, A.F. Epigenetic alterations in salivary gland tumors. Oral Dis. 2020, 26, 1610-1618. [CrossRef]

17. Cheng, Y.Y.; Jin, H.C.; Chan, M.W.Y.; Chu, W.K.; Grusch, M. Epigenetic biomarkers in cancer. Dis. Markers 2018, $2018,9864047$. [CrossRef]

18. Dawson, M.A.; Kouzarides, T. Cancer epigenetics: From mechanism to therapy. Cell 2012, 150, 12-27. [CrossRef] [PubMed]

19. Costa, F.F. Epigenomics in cancer management. Cancer Manag. Res. 2010, 2, 255-265. [CrossRef]

20. Esteller, M. Cancer epigenomics: DNA methylomes and histone-modification maps. Nat. Rev. Genet. 2007, 8, 286-298. [CrossRef]

21. Seto, E.; Yoshida, M. Erasers of histone acetylation: The histone deacetylase enzymes. Cold Spring Harb. Perspect. Biol. 2014, 6, a018713. [CrossRef]

22. Li, Y.; Seto, E. HDACs and HDAC inhibitors in cancer development and therapy. Cold Spring Harb. Perspect. Med. 2016, 6, a026831. [CrossRef] [PubMed] 
23. Wawruszak, A.; Kalafut, J.; Okon, E.; Czapinski, J.; Halasa, M.; Przybyszewska, A.; Miziak, P.; Okla, K.; Rivero-Muller, A.; Stepulak, A. Histone deacetylase inhibitors and phenotypical transformation of cancer cells. Cancers 2019, 11, 148. [CrossRef]

24. Slootweg, P.J.; El-Naggar, A.K. World Health Organization-4th edition of Head and Neck Tumor Classification: Insight into the consequential modifications. Virchows Arch. 2018, 472, 311-313. [CrossRef]

25. Theocharis, S.; Klijanienko, J.; Giaginis, C.; Rodriguez, J.; Jouffroy, T.; Girod, A.; Alexandrou, P.; Sastre-Garau, X. Histone deacetylase- 1 and -2 expression in mobile tongue squamous cell carcinoma: Associations with clinicopathological parameters and patients survival. J. Oral Pathol. Med. 2011, 40,706-714. [CrossRef]

26. Giaginis, C.; Alexandrou, P.; Delladetsima, I.; Giannopoulou, I.; Patsouris, E.; Theocharis, S. Clinical significance of histone deacetylase (HDAC)-1, HDAC-2, HDAC-4, and HDAC-6 expression in human malignant and benign thyroid lesions. Tumor Biol. 2014, 35, 61-71. [CrossRef]

27. Jang, J.Y.; Choi, N.; Ko, Y.H.; Chung, M.K.; Son, Y.I.; Baek, C.H.; Baek, K.H.; Jeong, H.S. Treatment outcomes in metastatic and localized high-grade salivary gland cancer: High chance of cure with surgery and post-operative radiation in T1-2 N0 high-grade salivary gland cancer. BMC Cancer 2018, 18, 672. [CrossRef]

28. Haderlein, M.; Scherl, C.; Semrau, S.; Lettmaier, S.; Uter, W.; Neukam, F.W.; Iro, H.; Agaimy, A.; Fietkau, R. High-grade histology as predictor of early distant metastases and decreased disease-free survival in salivary gland cancer irrespective of tumor subtype. Head Neck 2016, 38, E2041-E2048. [CrossRef] [PubMed]

29. Mutze, K.; Langer, R.; Becker, K.; Ott, K.; Novotny, A.; Luber, B.; Hapfelmeier, A.; Göttlicher, M.; Höfler, H.; Keller, G. Histone deacetylase (HDAC) 1 and 2 expression and chemotherapy in gastric cancer. Ann. Surg. Oncol. 2010, 17, 3336-3343. [CrossRef] [PubMed]

30. Seo, J.; Min, S.K.; Park, H.R.; Kim, D.H.; Kwon, M.J.; Kim, L.S.; Ju, Y.S. Expression of histone deacetylases HDAC1, HDAC2, HDAC3, and HDAC6 in invasive ductal carcinomas of the breast. J. Breast Cancer 2014, 17, 323-331. [CrossRef] [PubMed]

31. Staberg, M.; Michaelsen, S.R.; Rasmussen, R.D.; Villingshøj, M.; Poulsen, H.S.; Hamerlik, P. Inhibition of histone deacetylases sensitizes glioblastoma cells to lomustine. Cell. Oncol. 2017, 40, 21-32. [CrossRef] [PubMed]

32. Chrun, E.S.; Modolo, F.; Vieira, D.S.C.; Borges, L.S., Jr.; Castro, R.G.; Daniel, F.I. Immunoexpression of HDAC1, HDAC2, and HAT1 in actinic cheilitis and lip squamous cell carcinoma. Oral Dis. 2017, 23, 505-510. [CrossRef] [PubMed]

33. Han, Y.; Zhang, Y.; Yang, L.H.; Mi, X.Y.; Dai, S.D.; Li, Q.C.; Xu, H.T.; Yu, J.H.; Li, G.; Zhao, J.; et al. hua X-radiation inhibits histone deacetylase 1 and 2, upregulates Axin expression and induces apoptosis in non-small cell lung cancer. Radiat. Oncol. $2012,7,183$. [CrossRef] [PubMed]

34. Quint, K.; Agaimy, A.; Di Fazio, P.; Montalbano, R.; Steindorf, C.; Jung, R.; Hellerbrand, C.; Hartmann, A.; Sitter, H.; Neureiter, D.; et al. Clinical significance of histone deacetylases 1, 2, 3, and 7: HDAC2 is an independent predictor of survival in HCC. Virchows Arch. 2011, 459, 129-139. [CrossRef]

35. Halkidou, K.; Gaughan, L.; Cook, S.; Leung, H.Y.; Neal, D.E.; Robson, C.N. Upregulation and nuclear recruitment of HDACl in hormone refractory prostate cancer. Prostate 2004, 59, 177-189. [CrossRef]

36. Weichert, W.; Röske, A.; Gekeler, V.; Beckers, T.; Stephan, C.; Jung, K.; Fritzsche, F.R.; Niesporek, S.; Denkert, C.; Dietel, M.; et al. Histone deacetylases 1,2 and 3 are highly expressed in prostate cancer and HDAC2 expression is associated with shorter PSA relapse time after radical prostatectomy. Br. J. Cancer 2008, 98, 604-610. [CrossRef]

37. Weichert, W.; Denkert, C.; Noske, A.; Darb-Esfahani, S.; Dietel, M.; Kalloger, S.E.; Huntsman, D.G.; Köbel, M. Expression of class I histone deacetylases indicates poor prognosis in endometrioid subtypes of ovarian and endometrial carcinomas. Neoplasia 2008, 10, 1021-1027. [CrossRef]

38. Poyet, C.; Jentsch, B.; Hermanns, T.; Schweckendiek, D.; Seifert, H.H.; Schmidtpeter, M.; Sulser, T.; Moch, H.; Wild, P.J.; Kristiansen, G. Expression of histone deacetylases 1, 2 and 3 in urothelial bladder cancer. BMC Clin. Pathol. 2014, 14, 2753-2760. [CrossRef]

39. Suzuki, J.; Chen, Y.Y.; Scott, G.K.; DeVries, S.; Chin, K.; Benz, C.C.; Waldman, F.M.; Hwang, E.S. Protein acetylation and histone deacetylase expression associated with malignant breast cancer progression. Clin. Cancer Res. 2009, 15, 3163-3171. [CrossRef] [PubMed]

40. Langer, R.; Mutze, K.; Becker, K.; Feith, M.; Ott, K.; Höfler, H.; Keller, G. Expression of class I histone deacetylases (HDAC1 and HDAC2) in oesophageal adenocarcinomas: An immunohistochemical study. J. Clin. Pathol. 2010, 63, 994-998. [CrossRef]

41. Weichert, W.; Röske, A.; Gekeler, V.; Beckers, T.; Ebert, M.P.; Pross, M.; Dietel, M.; Denkert, C.; Röcken, C. Association of patterns of class I histone deacetylase expression with patient prognosis in gastric cancer: A retrospective analysis. Lancet Oncol. 2008, 9, 139-148. [CrossRef]

42. Weichert, W.; Röske, A.; Niesporek, S.; Noske, A.; Buckendahl, A.C.; Dietel, M.; Gekeler, V.; Boehm, M.; Beckers, T.; Denkert, C. Class I histone deacetylase expression has independent prognostic impact in human colorectal cancer: Specific role of class I histone deacetylases in vitro and in vivo. Clin. Cancer Res. 2008, 14, 1669-1677. [CrossRef]

43. Morine, Y.; Shimada, M.; Iwahashi, S.; Utsunomiya, T.; Imura, S.; Ikemoto, T.; Mori, H.; Hanaoka, J.; Miyake, H. Role of histone deacetylase expression in intrahepatic cholangiocarcinoma. Surgery 2012, 151, 412-419. [CrossRef]

44. Hayashi, A.; Horiuchi, A.; Kikuchi, N.; Hayashi, T.; Fuseya, C.; Suzuki, A.; Konishi, I.; Shiozawa, T. Type-specific roles of histone deacetylase (HDAC) overexpression in ovarian carcinoma: HDAC1 enhances cell proliferation and HDAC3 stimulates cell migration with downregulation of E-cadherin. Int. J. Cancer 2010, 127, 1332-1346. [CrossRef] [PubMed]

45. Krusche, C.A.; Wülfing, P.; Kersting, C.; Vloet, A.; Böcker, W.; Kiesel, L.; Beier, H.M.; Alfer, J. Histone deacetylase-1 and -3 protein expression in human breast cancer: A tissue microarray analysis. Breast Cancer Res. Treat. 2005, 90, 15-23. [CrossRef] 
46. Giaginis, C.; Damaskos, C.; Koutsounas, I.; Zizi-Serbetzoglou, A.; Tsoukalas, N.; Patsouris, E.; Kouraklis, G.; Theocharis, S. Histone deacetylase (HDAC)-1, $-2,-4$ and -6 expression in human pancreatic adenocarcinoma: Associations with clinicopathological parameters, tumor proliferative capacity and patients' survival. BMC Gastroenterol. 2015, 15, 148. [CrossRef] [PubMed]

47. Wu, L.M.; Yang, Z.; Zhou, L.; Zhang, F.; Xie, H.Y.; Feng, X.W.; Wu, J.; Zheng, S.S. Identification of histone deacetylase 3 as a biomarker for tumor recurrence following liver transplantation in HBV-associated hepatocellular carcinoma. PLoS ONE 2010, 5, e14460. [CrossRef]

48. Wilmott, J.S.; Colebatch, A.J.; Kakavand, H.; Shang, P.; Carlino, M.S.; Thompson, J.F.; Long, G.V.; Scolyer, R.A.; Hersey, P. Expression of the class 1 histone deacetylases HDAC8 and 3 are associated with improved survival of patients with metastatic melanoma. Mod. Pathol. 2015, 28, 884-894. [CrossRef]

49. Milde, T.; Oehme, I.; Korshunov, A.; Kopp-Schneider, A.; Remke, M.; Northcott, P.; Deubzer, H.E.; Lodrini, M.; Taylor, M.D.; Von Deimling, A.; et al. HDAC5 and HDAC9 in medulloblastoma: Novel markers for risk stratification and role in tumor cell growth. Clin. Cancer Res. 2010, 16, 3240-3252. [CrossRef]

50. Ouaïssi, M.; Sielezneff, I.; Silvestre, R.; Sastre, B.; Bernard, J.P.; Lafontaine, J.S.; Payan, M.J.; Dahan, L.; Pirrò, N.; Seitz, J.F.; et al. High histone deacetylase 7 (HDAC7) expression is significantly associated with adenocarcinomas of the pancreas. Ann. Surg. Oncol. 2008, 15, 2318-2328. [CrossRef] [PubMed]

51. Sudo, T.; Mimori, K.; Nishida, N.; Kogo, R.; Iwaya, T.; Tanaka, F.; Shibata, K.; Fujita, H.; Shirouzu, K.; Mori, M. Histone deacetylase 1 expression in gastric cancer. Oncol. Rep. 2011, 26, 777-782. [CrossRef] [PubMed]

52. Lee, H.H.; Seo, K.J.; An, C.H.; Kim, J.S.; Jeon, H.M. CD133 expression is correlated with chemoresistance and early recurrence of gastric cancer. J. Surg. Oncol. 2012, 106, 999-1004. [CrossRef]

53. Lutz, L.; Fitzner, I.C.; Ahrens, T.; Geißler, A.L.; Makowiec, F.; Hopt, U.T.; Bogatyreva, L.; Hauschke, D.; Werner, M.; Lassmann, S. Histone modifiers and marks define heterogeneous groups of colorectal carcinomas and affect responses to HDAC inhibitors in vitro. Am. J. Cancer Res. 2016, 6, 664-676.

54. Song, J.; Noh, J.H.; Lee, J.H.; Eun, J.W.; Ahn, Y.M.; Kim, S.Y.; Hyung Lee, S.; Park, W.S.; Yoo, N.J.; Lee, J.Y.; et al. Increased expression of histone deacetylase 2 is found in human gastric cancer. APMIS 2005, 113, 264-268. [CrossRef]

55. Fritzsche, F.R.; Weichert, W.; Röske, A.; Gekeler, V.; Beckers, T.; Stephan, C.; Jung, K.; Scholman, K.; Denkert, C.; Dietel, M.; et al. Class I histone deacetylases 1, 2 and 3 are highly expressed in renal cell cancer. BMC Cancer 2008, 8, 381. [CrossRef]

56. Shen, Y.F.; Wei, A.M.; Kou, Q.; Zhu, Q.Y.; Zhang, L. Histone deacetylase 4 increases progressive epithelial ovarian cancer cells via repression of p21 on fibrillar collagen matrices. Oncol. Rep. 2016, 35, 948-954. [CrossRef]

57. Wang, L.; Zou, X.; Berger, A.D.; Twiss, C.; Peng, Y.; Li, Y.; Chiu, J.; Guo, H.; Satagopan, J.; Wilton, A.; et al. Increased expression of histone deacetylaces (HDACs) and inhibition of prostate cancer growth and invasion by HDAC inhibitor SAHA. Am. J. Transl. Res. 2009, 1, 62-71. [PubMed]

58. Sakuma, T.; Uzawa, K.; Onda, T.; Shiiba, M.; Yokoe, H.; Shibahara, T.; Tanzawa, H. Aberrant expression of histone deacetylase 6 in oral squamous cell carcinoma. Int. J. Oncol. 2006, 29, 117-124. [CrossRef] [PubMed]

59. Suraweera, A.; O'Byrne, K.J.; Richard, D.J. Combination therapy with histone deacetylase inhibitors (HDACi) for the treatment of cancer: Achieving the full therapeutic potential of HDACi. Front. Oncol. 2018, 8, 92. [CrossRef]

60. Wagner, V.P.; Martins, M.D.; Guimaraes, D.M.; Vasconcelos, A.C.; Meurer, L.; Vargas, P.A.; Fonseca, F.P.; Squarize, C.H.; Castilho, R.M. Reduced chromatin acetylation of malignant salivary gland tumors correlates with enhanced proliferation. J. Oral Pathol. Med. 2017, 46, 792-797. [CrossRef] [PubMed]

61. Ahn, M.Y.; Yoon, J.H. Histone deacetylase 7 silencing induces apoptosis and autophagy in salivary mucoepidermoid carcinoma cells. J. Oral Pathol. Med. 2017, 46, 276-283. [CrossRef]

62. Wagner, V.P.; Martins, M.D.; Martins, M.A.T.; Almeida, L.O.; Warner, K.A.; Nör, J.E.; Squarize, C.H.; Castilho, R.M. Targeting histone deacetylase and NFKB signaling as a novel therapy for mucoepidermoid carcinomas. Sci. Rep. 2018, 8, 2065. [CrossRef]

63. Almeida, L.O.; Guimarães, D.M.; Martins, M.D.; Martins, M.A.T.; Warner, K.A.; Nör, J.E.; Castilho, R.M.; Squarize, C.H. Unlocking the chromatin of adenoid cystic carcinomas using HDAC inhibitors sensitize cancer stem cells to cisplatin and induces tumor senescence. Stem Cell Res. 2017, 21, 94-105. [CrossRef] [PubMed]

64. Guimarães, D.M.; Almeida, L.O.; Martins, M.D.; Warner, K.A.; Silva, A.R.S.; Vargas, P.A.; Nunes, F.D.; Squarize, C.H.; Nör, J.E.; Castilho, R.M. Sensitizing mucoepidermoid carcinomas to chemotherapy by targeted disruption of cancer stem cells. Oncotarget 2016, 7, 42447-42460. [CrossRef]

65. Yang, S.; Nan, P.; Li, C.; Lin, F.; Li, H.; Wang, T.; Zhou, C.; Zhang, X.; Meng, X.; Qian, H.; et al. Inhibitory effect of chidamide on the growth of human adenoid cystic carcinoma cells. Biomed. Pharmacother. 2018, 99, 608-614. [CrossRef] 